\title{
The rational design of modified Cinchona alkaloid catalysts. Application to a new asymmetric synthesis of chiral chromanes
}

\author{
Alain Merschaert, ${ }^{\mathrm{a}, *}$ Pieter Delbeke, ${ }^{\mathrm{a}}$ Désiré Daloze ${ }^{\mathrm{b}}$ and Georges Dive ${ }^{\mathrm{c}}$ \\ ${ }^{a}$ Global Chemical Product Research \& Development, Lilly Research Laboratories, Lilly Development Centre S.A., \\ Rue Granbonpré 11, B-1348 Mont-Saint-Guibert, Belgium \\ ${ }^{\mathrm{b}}$ Service de Chimie Organique, Faculté des Sciences, Université Libre de Bruxelles, Av. F.D. Roosevelt 50, B-1050 Bruxelles, Belgium \\ ${ }^{\mathrm{c}}$ Centre d'Ingéniérie des Protéines, Université de Liège, Bâtiment B6, Allée de la Chimie 3, B-4000 Liège, Belgium
}

Received 25 March 2004; revised 14 April 2004; accepted 16 April 2004

\begin{abstract}
A new asymmetric synthesis of 2-substituted chiral chromanes has been achieved. The key step is the intramolecular conjugate addition of a phenolic nucleophile on a $\alpha, \beta$-unsaturated ester catalyzed by Cinchona alkaloids. The high ee's obtained with cinchonine and its derivatives have been rationalized by ab initio quantum chemistry calculations of transition state structures.
\end{abstract}

(C) 2004 Elsevier Ltd. All rights reserved.

Functionalized chromanes possess potentially useful biological properties. ${ }^{1}$ In the scope of a research program, we developed earlier the synthesis of 2,6-disubstituted-chromanes from 6-substituted chromanones ${ }^{2}$ (Fig. 1).

Although high overall yields of racemic material were obtained, this approach suffered from the need to perform an optical resolution in the last step of the synthesis.

In order to improve the productivity of the process without having to develop a new route, we sought to utilize a chiral base in the Wittig-oxa-Michael step (Fig. 2). The results of those efforts are reported herein. Initially very low enantioselectivities (ca. $28 \%$ ee with cinchonine) were obtained in a tandem process by heating a mixture of lactol 1, phosphorane, and cinchonine to 80$100{ }^{\circ} \mathrm{C}$. In this temperature range, we observed that the phosphorane alone was able to catalyze the cyclization thus competing with the chiral catalyst. Therefore, we modified the procedure and performed the reaction sequentially: (i) the Wittig step was carried out at ambient temperature (ii) the remaining phosphorane and the triphenylphosphine oxide by-product were removed by silica gel treatment, and (iii) the chiral

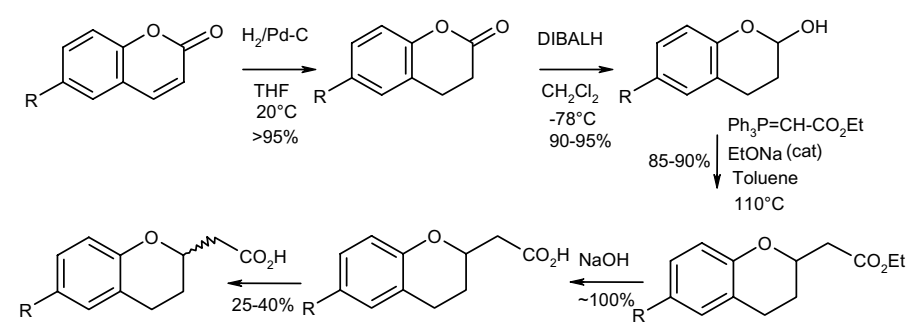

Figure 1.

Keywords: Alkaloids; oxa-Michael; Asymmetric; Catalysis.

* Corresponding author. Tel.: +32-10-47-70-21; fax: +32-10-47-63-15; e-mail: merschaert_alain@lilly.com 


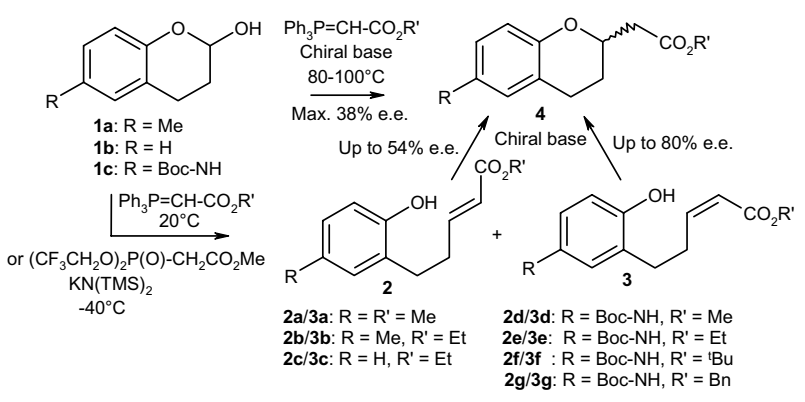

Figure 2.

catalyst was added to the crude mixture of olefins ( $\sim 90 \% \mathrm{E}$ isomer) and the solution heated to $80-100{ }^{\circ} \mathrm{C}$. Unfortunately, we obtained only slightly better results (ca. 38\% ee with cinchonine). Anyway, simple use of cinchonine in the Wittig-oxa-Michael step allowed us to increase the overall yield by $10-15 \%$. After separation of the $(E)$ - and $(Z)-\alpha, \beta$-unsaturated esters $\mathbf{2} \mathbf{e}-\mathbf{3 e}$, we found that these compounds cyclized into the opposite enantiomers: with cinchonine $(5-10 \mathrm{~mol} \%)$ as catalyst, the $E$ isomer 2e gave the $S$-chromane 4 (44\% ee) and the $Z$ olefin 3 e afforded the $R$ enantiomer $(66 \%$ ee $)$. It is worth mentioning that among Cinchona alkaloids cinchonine gave the best results for both $E$ and $Z$ isomers (cinchonine $>$ quinidine $>$ cinchonidine $\gg$ quinine). On the other hand, we attempted to increase the enantioselectivity by modifying the alkyl chain (methyl, tertbutyl, and benzyl) of the ester function but with little success: up to $67 \%$ ee for the $Z$ benzyl ester $3 g$ and $54 \%$ ee for the $E$ tert-butyl ester $\mathbf{2 f}$.

We performed a broader screening of chiral bases and solvents ${ }^{3}$ but none of the systems studied could improve the results obtained with readily available cinchonine. In many experiments performed on the $Z$ substrates, we observed the formation of the $E$ isomer. Control experiments showed that this latter product is not formed by direct isomerization of the $Z$ substrate $^{4}$ or by retro-Michael on the final chromane. ${ }^{5}$ We assumed therefore that protonation of the ester enolate formed after cyclization was too slow in aprotic solvents thus allowing retro-Michael reaction leading to the formation of the $E$ isomer.
Table 1. Modifications of cinchonine at carbon-9

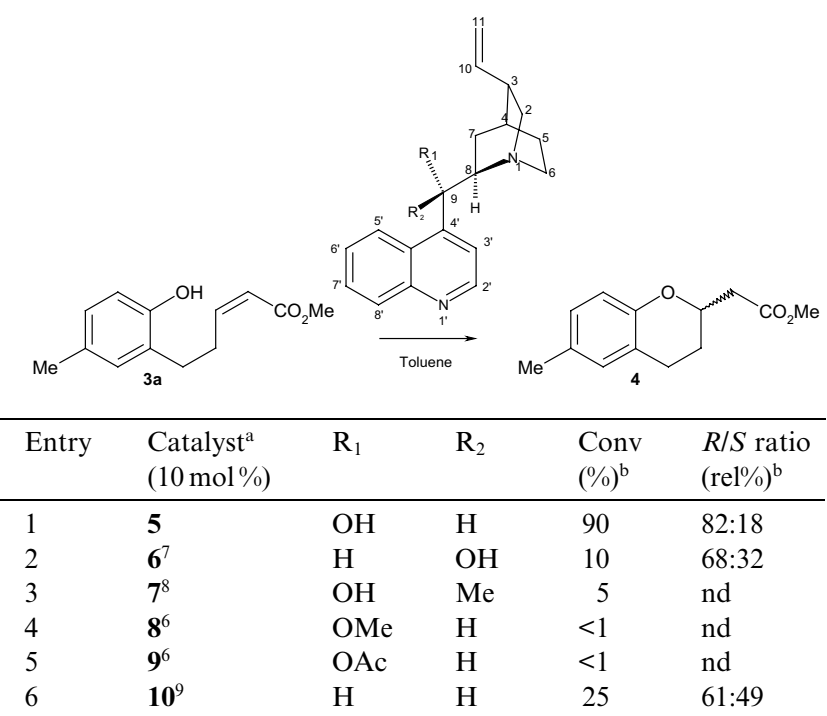

${ }^{\text {a }}$ Reactions were carried out in toluene $(0.5 \mathrm{M})$ at $110^{\circ} \mathrm{C}$ under $\mathrm{N}_{2}$ for $48 \mathrm{~h}$.

${ }^{\mathrm{b}}$ Determined by HPLC - Column Chiralcel OD, elution with $1 \mathrm{~mL} /$ min $n$-heptane/EtOH/diethylamine 99/1/0.2, UV detection at $235 \mathrm{~nm}$.

We decided thus to focus on cinchonine (5) and evaluated first modifications around chiral carbon- $-9^{6}$ (Table 1).

Table 1 shows all the modifications envisaged in catalysts 6-10. It is noteworthy that increase of steric hindrance and conformational constrain (entry 3), Ofunctionalization (entries 4 and 5) and de-hydroxylation (entry 6) have a large negative effect. The presence of a conformationally mobile free hydroxy group is thus needed in the catalyst to achieve both good kinetics and enantioselectivity.

We envisaged then the modification of the vinyl side chain of cinchonine ${ }^{10} \mathbf{5}$ and selected the aldehyde $\mathbf{1 2}$ as the key intermediate of our approach (Fig. 3).

We found that epimerization occurs at carbon-3 during the periodate oxidation step ${ }^{11}$ and developed an efficient crystallization in diisopropylether to obtain highly pure

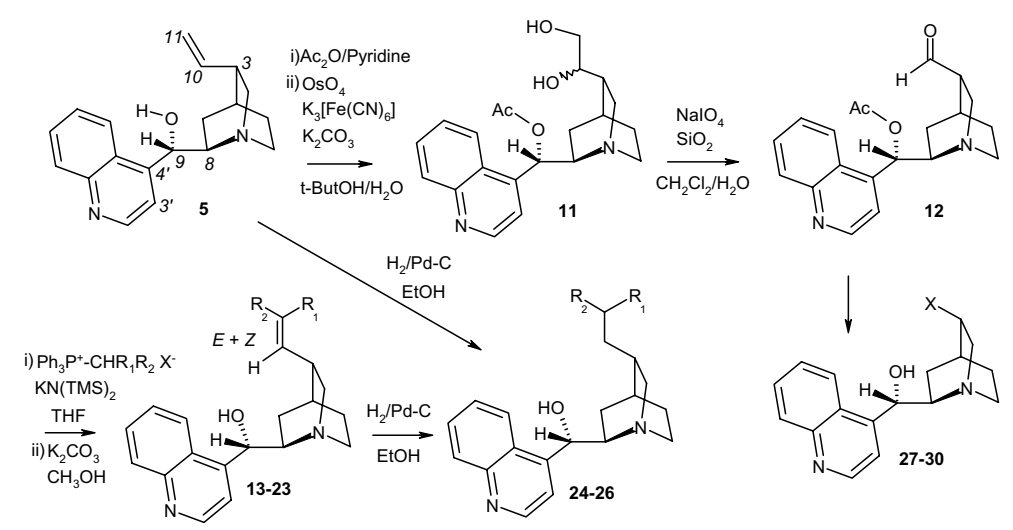

Figure 3. Preparation of $\mathrm{C} 3$-modified catalysts. 
Table 2. Preparation of C3-modified catalysts

\begin{tabular}{|c|c|c|c|c|c|}
\hline Entry & Compound & $\mathrm{R}_{1}$ & & $\mathrm{R}_{2}$ & Yield $(\%)^{\mathrm{a}}$ \\
\hline 1 & 13 & $\mathrm{H}$ & & $\mathrm{Me}$ & 25 \\
\hline 2 & 14 & $\mathrm{Me}$ & & $\mathrm{H}$ & 45 \\
\hline 3 & 15 & $\mathrm{H} / \mathrm{Et}^{\mathrm{b}}$ & & $\mathrm{Et} / \mathrm{H}^{\mathrm{b}}$ & 80 \\
\hline 4 & 16 & $i-\operatorname{Pr} / \mathrm{H}^{\mathrm{b}}$ & & $\mathrm{H} / i-\operatorname{Pr}^{\mathrm{b}}$ & 70 \\
\hline 5 & 17 & $\mathrm{H}$ & & $\mathrm{Ph}$ & 68 \\
\hline 6 & 18 & $\mathrm{Ph}$ & & $\mathrm{H}$ & 12 \\
\hline 7 & 19 & $\mathrm{Me}$ & & $\mathrm{Me}$ & 30 \\
\hline 8 & 20 & $\mathrm{Me} / \mathrm{Et}$ & & $\mathrm{Et} / \mathrm{Me}$ & $<5$ \\
\hline 9 & 21 & & $c$-Hex & & $<5$ \\
\hline 10 & 22 & & $c-\operatorname{Pr}$ & & $\sim 0$ \\
\hline 11 & 23 & $\mathrm{Ph}$ & & $\mathrm{Ph}$ & $<5$ \\
\hline 12 & 24 & $\mathrm{H}$ & & $\mathrm{H}$ & $95^{\mathrm{c}}$ \\
\hline 13 & 25 & $\mathrm{Me}$ & & $\mathrm{Me}$ & 85 \\
\hline \multirow[t]{2}{*}{14} & 26 & $\mathrm{H}$ & & $\mathrm{Ph}$ & 90 \\
\hline & & & $\mathrm{X}$ & & \\
\hline 15 & 27 & & $\mathrm{H}$ & & 60 \\
\hline 16 & 28 & & $\mathrm{CH}_{2} \mathrm{OH}$ & & 95 \\
\hline 17 & 29 & & $\mathrm{CN}$ & & 60 \\
\hline 18 & 30 & & $\mathrm{CHO}$ & & 90 \\
\hline
\end{tabular}

${ }^{\mathrm{a}}$ Isolated unoptimized yields.

${ }^{\mathrm{b}}$ E/Z mixture ( $\sim 1: 2$ by ${ }^{1} \mathrm{H}$ NMR) could not be separated.

${ }^{\mathrm{c}}$ Commercially available at $97 \%$ purity (Aldrich).

12. Catalysts 13-23 (Table 2) were prepared by reaction of 12 with ca. 3 equiv of the Wittig reagents prepared from the corresponding phosphonium halides and LHMDS. $^{12}$

We obtained about $80 \%$ yield for the mono-substituted compounds as $E / Z$ mixtures (entries 1-6) but only the 11-methyl and 11-phenyl derivatives could be separated by chromatography on silica gel. With the exception of the dimethyl compound 19, only traces of the 11,11disubstituted derivatives were obtained (entries 8-11). In these unsuccessful experiments, most recovered aldehyde 12 was largely epimerized at carbon-3. Cinchonine (5), 17, and 19 were hydrogenated with $10 \% \mathrm{Pd}-\mathrm{C}$ to afford the saturated catalysts 24-26 in high yield (entries 12-14). From the aldehyde 12, we prepared also the catalysts $28,{ }^{13} 29,{ }^{13}$ and 30 in order to evaluate electronic effects on the quinuclidine nitrogen ${ }^{14}$ and the catalyst $27^{13}$ to assess lack of substitution at carbon-3 of the quinuclidine ring.

These catalysts were tested in the cyclization of model $Z$ and $E$ esters 2a and 3a. ${ }^{15}$ Reactions were carried out at a lower temperature $\left(80^{\circ} \mathrm{C}\right)$ to better discriminate the effects of our modifications on the conversion and to minimize possible retro-Michael side reaction ${ }^{16}$ occurring at higher temperature. As shown in Table 3, modifications at carbon-3 generally affect conversion and enantioselectivity. Globally, the introduction of alkyl or aryl groups on the vinyl side chain of the catalyst (entries 2-8) had a positive effect on enantioselectivity and a negative impact on conversion. The best enantioselectivities were obtained with the bulkiest groups (entries 4-7) albeit at low conversion. For both methyl and phenyl groups, the $Z$ geometry gave better enantioselectivity $(14>13$ and $18>17)$. Dialkylation at the terminal position of the olefin was also beneficial (entry 8).
Table 3. Cyclization of $Z$ ester model 3a with C3-modified catalysts

\begin{tabular}{|c|c|c|c|}
\hline Entry & $\begin{array}{l}\text { Catalyst } \\
(10 \mathrm{~mol} \%)^{\mathrm{a}}\end{array}$ & Conversion $(\%)^{\mathrm{b}}$ & $\begin{array}{l}R / S \text { ratio } \\
(\mathrm{rel} \%)^{\mathrm{b}}\end{array}$ \\
\hline 1 & 5 & 45 & $82: 18$ \\
\hline 2 & 13 & 37 & $78: 22$ \\
\hline 3 & 14 & 30 & $83: 17$ \\
\hline 4 & 15 & 44 & $87: 13$ \\
\hline 5 & 16 & 34 & $89: 11$ \\
\hline 6 & 17 & 23 & $88: 12$ \\
\hline 7 & 18 & 20 & $90: 10$ \\
\hline 8 & 19 & 44 & $87: 13$ \\
\hline 9 & 24 & 75 & $86: 14$ \\
\hline 10 & 25 & 45 & $88: 12$ \\
\hline 11 & 26 & 35 & $90: 10$ \\
\hline 12 & 27 & 35 & $65: 35$ \\
\hline 13 & 28 & 42 & $87: 13$ \\
\hline 14 & 29 & $<2$ & nd \\
\hline 15 & 30 & $<2$ & nd \\
\hline
\end{tabular}

On the other hand, hydrogenation of the vinyl group (entries 9-11) increased conversion and enantioselectivity, especially for the least hindered catalyst $(\mathbf{2 4}>\mathbf{5})$.

We assume that the intrinsically higher steric hindrance of the saturated compounds favors discrimination between the transition states. Higher conversions are explained by an increase of the nitrogen basicity due to a higher $+i$ effect at position-3. ${ }^{17}$ The poor results obtained with catalyst 27 reinforce our assumption about the need for steric hindrance at position-3. We have also shown that introduction of a polar hydroxy function is tolerated (entry 13) contrary to strong electron-withdrawing groups, which give significantly poorer results (entries 14 and 15). Catalysts 29-30 are most probably not basic enough to deprotonate the phenolic substrate. $^{14}$

As illustrated in Table 4, the effect of a structural modification of the catalyst on the $E$ ester 2a cyclization is relatively similar to that observed for the $Z$ derivative.

Steric hindrance (entries 2, 4, and 5) and hydrogenation (entries 6-8) of the vinyl side chain have generally a positive effect whereas electron-withdrawing groups (entries 11 and 12) lead to low conversions. As observed in our earlier studies, cyclization of the $E$ isomer is always faster but less enantioselective. Of the catalysts tested, $\mathbf{2 6}$ gave the highest enantioselectivities for both $Z$ ( $80 \%$ ee) and $E(52 \%$ ee) substrates.

In order to rationalize the results obtained with cinchonine and to help design better catalysts, we performed a molecular modeling study. Numerous conformational studies have been conducted on Cinchona alkaloids. ${ }^{18}$ The relative populations of the more 
Table 4. Cyclization of $E$ ester model 2a with C3-modified catalysts<smiles>CC(=O)C=CCCc1cc(C)ccc1O</smiles>

\begin{tabular}{llcl}
\hline Entry & $\begin{array}{l}\text { Catalyst } \\
(10 \mathrm{~mol} \%)^{\mathrm{a}}\end{array}$ & $\begin{array}{l}\text { Conversion } \\
(\%)^{\mathrm{b}}\end{array}$ & $\begin{array}{l}R / S \text { ratio } \\
\left(\mathrm{rel}^{\mathrm{b}}\right)^{\mathrm{b}}\end{array}$ \\
\hline 1 & $\mathbf{5}$ & 95 & $30: 70$ \\
2 & $\mathbf{1 3}$ & 58 & $31: 69$ \\
3 & $\mathbf{1 7}$ & 70 & $40: 60$ \\
4 & $\mathbf{1 8}$ & 35 & $26: 74$ \\
5 & $\mathbf{1 9}$ & 60 & $28: 72$ \\
6 & $\mathbf{2 4}$ & 100 & $25: 75$ \\
7 & $\mathbf{2 5}$ & 75 & $27: 73$ \\
8 & $\mathbf{2 6}$ & 82 & $24: 76$ \\
9 & $\mathbf{2 7}$ & 50 & $41: 59$ \\
10 & $\mathbf{2 8}$ & 80 & $32: 68$ \\
11 & $\mathbf{2 9}$ & 3 & $\mathrm{nd}$ \\
12 & $\mathbf{3 0}$ & 10 & $30: 70$ \\
\hline
\end{tabular}

${ }^{a}$ Reactions were carried out in toluene $(0.5 \mathrm{M})$ at $80^{\circ} \mathrm{C}$ under $\mathrm{N}_{2}$ for $24 \mathrm{~h}$.

${ }^{\mathrm{b}}$ Determined by HPLC — Column Chiralcel OD, elution with $1 \mathrm{~mL} /$ min $n$-heptane/EtOH/diethylamine 99/1/0.2, UV detection at $235 \mathrm{~nm}$.

stable conformations are very sensitive to the environmental variations such as $\mathrm{pH}$, solvent polarity or $\mathrm{H}$ bonding. ${ }^{19}$ It is however hazardous to limit the study of a catalyst-substrate interaction to the most stable conformers of the free alkaloid as the relative differences between their energies are relatively low compared to the energies of transition states. ${ }^{20}$

Therefore, we decided to use ab initio quantum chemistry calculations, which build step by step models of the substrate-catalyst complex starting with the key hydroxy and amino groups of the alkaloid. ${ }^{21}$ A potential energy map of cinchonine has been calculated for the torsion angles $\phi 1\left(\mathrm{C}^{\prime}-\mathrm{C} 9-\mathrm{C} 8-\mathrm{N} 1\right)$ and $\phi 2\left(\mathrm{C}^{\prime}-\mathrm{C}^{\prime}{ }^{\prime}-\right.$ C9-C8) by optimization of all the other $3 n-8$ degrees of freedom. As the differences in free energy between 6 of the $8 \mathrm{minima}$ found are $<2.5 \mathrm{kcal} / \mathrm{mol}$, we can conclude that several of them are energetically accessible for the intramolecular oxa-Michael reaction. We found two possible transition states for the cyclization of the $Z$ substrate. Both involve the formation of a tight ion-pair between the basic nitrogen of cinchonine and the phenolic group of the substrate as well as a large deformation of the quinuclidine ring during cyclization. Torsion angle $\phi 1$ of cinchonine remains close to $300^{\circ}$ whereas $\phi 2$ varies from $-20^{\circ}$ to $+40^{\circ}$. Transition state (TS) I is stabilized by hydrogen bonding between the hydroxy group of the catalyst and the carbonyl function of the $\alpha, \beta$-unsaturated ester. Preferential formation of the $R$ enantiomer is explained by a lower steric repulsion between the vinyl and quinoline groups (Fig. 4). Indeed, the distance between carbons 11 and $6^{\prime}$ in the pro- $R$ and pro- $S$ TS I are, respectively, $\sim 9.3$ and $\sim 4.8 \AA$. This TS is thus in agreement with the best ee obtained with the more hindered C-11 substituted catalysts.

In the other energetically favored TS (II) leading to the $R$ enantiomer, the hydroxy group of cinchonine takes

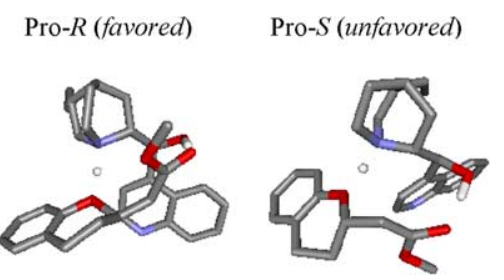

Figure 4. Possible transition state $\mathbf{I}$ for $Z$ ester isomer 3a.

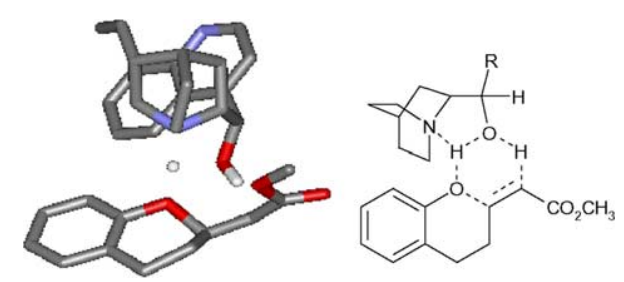

Figure 5. Possible transition state II for $Z$ ester isomer 3a.

part in a concerted mechanism (Fig. 5). This pathway avoiding the formation of a charged ester enolate after cyclization is energetically favored in apolar solvents.

TS II might thus explain the much lower extend of retroMichael side reaction observed for cinchonine and its derivatives as compared to most other aminoalcohols. As for the less enantioselective $E$ isomer cyclizations we identified only a structure very similar to $\mathbf{I}$, we tentatively propose II as the preferred transition state for the cyclization of $Z$ compounds.

In conclusion, we have achieved a new asymmetric synthesis of 2-substituted chiral chromanes. The key step is the intramolecular conjugate addition of a phenolic nucleophile on a $\alpha, \beta$-unsaturated ester. To the best of our knowledge, it is the first example of asymmetric catalysis of an exo-trig ${ }^{22}$ cyclization for an oxygen nucleophile. An extensive study of the effect of the catalyst's structure on the enantioselectivity of a model reaction was achieved. We have shown that the highest ee's are obtained with the readily available Cinchona alkaloids and some of their derivatives. Finally, the experimental results have been rationalized by $a b$ initio quantum chemistry calculations of transition state structures.

\section{Acknowledgements}

Dr. Georges Dive is Research Associate of the F.N.R.S. and is thankful for PAI no P5/33.

\section{References and notes}

1. (a) Browers, W. S.; Ohta, T.; Cleere, J. S.; Marsella, P. A. Science 1976, 193, 542-547; (b) Schweizer, E. E.; MeederNycz, O. In Chromenes, Chromanes and Chromones; Ellis, G. P., Ed.; Wiley-Interscience: New York, 1977; pp 11- 
139; (c) Ellis, G. P.; Lockhart, I. M. Chromanes and Tocopherols; Wiley-Interscience: New York, 1981; (d) Broggini, G.; Folcio, F.; Sardone, N.; Sonzogni, M.; Zecchi, G. Tetrahedron: Asymmetry 1996, 7, 797-806, and references cited therein.

2. Antoine, L.; Boquel, P.; Borghese, A.; Gorissen, H.; Khau, V. V.; Martinelli, M.; Merschaert, A.; Ruhter, G.; Rypens, C. PCT Int. Appl. WO 094334, 2001; Chem. Abstr. 2001, 136, 37512.

3. Merschaert, A. Ph.D. Thesis, University of Brussels, 2001. Bases: ephedrine and derivatives (4-34\% ee), $(S)$-prolinol and derivatives (6-36\% ee), cis-1-ethyl-4-hydroxy-L-prolinol $(20 \%$ ee), $(R)$-3-hydroxyquinuclidine $(\sim 0 \%$ ee). Solvents: toluene-chlorobenzene $\gg \mathrm{THF}$-dioxane $\gg \mathrm{EtOH}$.

4. The $E$ isomer was not detected after refluxing the $O$-acetyl $Z \alpha, \beta$-unsaturated ester with cinchonine in toluene for $48 \mathrm{~h}$.

5. Neither ring-opening products nor loss of enantiomeric purity was observed after refluxing the chromane with cinchonine in toluene for $48 \mathrm{~h}$.

6. Hiemstra, H.; Wijnberg, H. J. Am. Chem. Soc. 1981, 103, 417-430.

7. Kowalik, J. T.; Lipinska, T.; Oleksyn, B. J.; Sliwinski, J. Enantiomer 1999, 4, 389-410.

8. Lämmerhofer, M.; Maier, N. PCT Int. Appl. WO 46557, 1997.

9. Obtained by Pd-catalyzed hydrogenolysis of $O$-tosylcinchonine prepared as described in Ref. 7.

10. (a) Braje, W.; Frackenpohl, J.; Langer, P.; Hoffmann, H. M. R. Tetrahedron 1998, 54, 3495-3512; (b) Langer, P.; Hoffmann, H. M. R. Tetrahedron 1997, 53, 9145-9158; (c) Schrake, O.; Braje, W.; Hoffmann, H. M. R.; Wartchow, R. Tetrahedron: Asymmetry 1998, 9, 3717-3722; (d) Schrake, O.; Rahn, V. S.; Frackenpohl, J.; Braje, W. M.; Hoffmann, H. M. R. Org. Lett. 1999, 1, 1607-1610; (e) Arrington, M. P.; Bennani, Y. L.; Göbel, T.; Walsh, P.; Zhao, S. H.; Sharpless, K. B. Tetrahedron Lett. 1993, 34, 7375-7378.

11. Despite using the optimized conditions described in Ref. $10 \mathrm{a}$, we obtained up to $20 \mathrm{~mol} \%$ of the unwanted 3-epimer.

12. A large excess of the Wittig reagent is required to achieve complete conversion of the aldehyde.

13. Catalyst $\mathbf{2 8}$ was prepared by reduction of $\mathbf{1 2}$ with $\mathrm{NaBH} 4$ in methanol followed by deprotection with $\mathrm{K}_{2} \mathrm{CO}_{3} .29$ was obtained by refluxing 12 with $\mathrm{NH}_{2} \mathrm{OH} \cdot \mathrm{HCl}$ in formic acid for $1 \mathrm{~h}$ followed by deprotection as above. 27 was obtained by decarbonylation of 12 with $\left(\mathrm{Ph}_{3} \mathrm{P}\right)_{3} \mathrm{RhCl}$ in toluene at $70^{\circ} \mathrm{C}$ for $20 \mathrm{~h}$ followed by deprotection as above.

14. Introduction of electron-withdrawing groups ot carbon-3 has a very significant effect on quinuclidinic nitrogen basicity. See: Drzewiczak, C.; Suszko-Purzycka, A.; Skolik, J. Pol. J. Chem. 1993, 67, 45-52, Calculated (ACD/ Log D Suite software, Adv. Chem. Dev. Inc.) $\mathrm{p} K_{\mathrm{a}}$ values for 27, 28, 29, and $\mathbf{3 0}$ are, respectively, 10.09, 9.29, 6.79, and $9.02( \pm 0.4)$.

15. The $Z$ methyl ester $3 \mathbf{a}$ was selected as it is readily obtained by reaction of 1 with bis(2,2,2-trifluoroethyl)(methoxycarbonyl-methyl)phosphonate according to Still, W. C.; Gennari, C. Tetrahedron Lett. 1983, 24, 4405-4408, It offered also the best peaks resolution in our chiral HPLC method.

16. These conditions were selected based on our initial studies. We often observed significant decrease of ee above $100^{\circ} \mathrm{C}$.

17. Calculated (ACD) $\mathrm{p} K_{\mathrm{a}}$ values: 9.99 for $\mathbf{2 4}$ and 9.18 for $\mathbf{5}$.

18. (a) Dijkstra, G. D. H.; Kellogg, R. M.; Wynberg, H.; Svendsen, J. S.; Marko, I.; Sharpless, K. B. J. Am. Chem Soc. 1989, 111, 8069-8076; (b) Dijkstra, G. D. H.; Kellogg, R. M.; Wynberg, H. J. Org. Chem. 1990, 55, 6121-6131; (c) Dijkstra, G. D. H.; Kellogg, R. M.; Wynberg, H. Rec. Trav. Chim. Pays-Bas 1989, 108, 195204; (d) Oleksyn, B. J.; Suszko-Purzycka, A.; Dive, G.; Lamotte-Brasseur, J. J. Pharm. Sci. 1992, 81, 122-127.

19. (a) Bürgi, T.; Baiker, A. J. Am. Chem. Soc. 1998, 120, 12920-12926; (b) Berg, U.; Aune, M.; Matsson, O. Tetrahedron Lett. 1995, 36, 2137-2140.

20. Uccello-Barretta, G.; Balzano, F.; Quintavalli, C.; Salvadori, P. J. Org. Chem. 2000, 65, 3596-3602.

21. The calculations were performed with GAUSSIAN94. For all the systems, a full geometry optimization was performed at the Hartree-Fock level within the minimal basis set MINI-1'. For the starting models involving water or simple amino-alcohols as catalysts, a full optimization within the double 6-31G basis set was also performed. The transition states (TS) were first optimized and the related minima were obtained by following the intrinsic reaction coordinate (IRC) from this TS. For details on similar approaches, see: Dive, G.; Dehareng, D. Int. J. Quant. Chem. 1999, 73, 161-174.

22. Baldwin, J. J. Chem. Soc., Chem. Commun. 1976, 734-737. 